\title{
CIDADANIA, POLÍTICAS DE IDENTIDADE E RENOVAÇÃO POLÍTICA: UM DEBATE À LUZ DA TEORIA DA JUSTIÇA DE JOHN RAWLS
}

\author{
CIUDADANÍA, POLÍTICAS DE IDENTIDAD Y RENOVACIÓN POLÍTICA:UN \\ DEBATE A LA LUZ TEORÍA DE LA JUSTICIA DE JOHN RAWLS
}

\author{
CITIZENSHIP, IDENTITY POLICIES AND POLICY RENEWAL: A DEBATE IN THE \\ LIGHT OF JOHN RAWLS' THEORY OF JUSTICE
}

Luana Darby Nayrra da Silva BARBOSA ${ }^{1}$

RESUMO: Este presente artigo objetiva analisar a concepção de justiça nos termos do liberalismo igualitário concebido pelo filósofo inglês John Rawls (1921-2002) com a cidadania brasileira, identificando nesta uma estrutura procedimental não regular, que não obedece a ordem lexical de conquistas de direitos universais inspirados nos ideais liberais, principalmente por se tratar de um país que muito tardiamente abriu mão de uma economia escravocrata. Partindo deste fato, apresentamos duas situações de atuação política que atribuímos como parte do contexto dos problemas sociais no país e o exercício da cidadania: destacamos o movimento LGBT, uma população que demanda por reconhecimento e direitos sociais. Em seguida, chamamos a atenção para a tendência da renovação política, a partir da formação das organizações suprapartidárias nos últimos anos, com a intenção de oxigenar a atividade política, em um momento político no qual as instituições públicas perdem progressivamente a credibilidade e a confiança da população.

PALAVRAS-CHAVE: Cidadania. Movimento LGBT. Movimentos de renovação política. Teoria da justiça.

RESUMEN: Este artículo tiene como objetivo analizar la concepción de la justicia en términos de liberalismo igualitario concebido por el filósofo inglés John Rawls (1921-2002) con la ciudadanía brasileña, identificando en esto una estructura procesal no regular que no obedece el orden léxico de los logros de los derechos universales inspirado en los ideales liberales, principalmente porque es un país que muy tarde consoló una economía esclava. Partiendo de este hecho, presentamos dos situaciones de acción política que atribuimos como parte del contexto de los problemas sociales en el país y el ejercicio de la ciudadanía: destacamos el movimiento LGBT, una población que exige reconocimiento y derechos sociales. A continuación, llamamos la atención sobre la tendencia de la renovación política, desde la formación de organizaciones suprapartidistas en los últimos años, con la intención de oxigenar la actividad política, en un momento político en el que las instituciones públicas pierden credibilidad y confianza de la población.

PALABRAS CLAVE: Ciudadanía. Movimiento LGBT. Movimientos de renovación política. Teoría de la justicia.

${ }^{1}$ Universidade Estadual Paulista (UNESP), Araraquara - SP - Brasil. Mestranda em Ciências Sociais. ORCID: https://orcid.org/0000-0001-5579-7967.E-mail: darbyn_luana@hotmail.com 
ABSTRACT: This article aims to analyze the concept of justice in terms of egalitarian liberalism conceived by the english philosopher John Rawls (1921-2002) with brazilian citizenship, identifying in it a non-regular procedural structure that does not obey the lexical order of conquests of universal rights inspired by liberal ideals, mainly because it is a country that very late gave up a slave-like economy. Based on this fact, we present two situations of political action that we attribute as part of the context of social problems in the country and the exercise of citizenship: we highlight the LGBT movement, a population that demands recognition and social rights. Next, we call attention to the trend of political renewal, based on the formation of supra-partisan organizations in recent years, with the intention of oxygenating political activity in a political moment in which public institutions progressively lose credibility and trust of the population.

KEYWORDS: Citizenship. LGBT movement. Political renewal movements. Theory of justice.

\section{Introdução}

A comunidade política é caracterizada por sua organização em torno de valores culturais compartilhados entre os membros de um mesmo território, partilhando de sentidos de solidariedade, identidade e interesses comuns em torno de uma vida boa. O liberalismo político, corrente que frequentemente aparece na esteira dos governos democráticos, vem desempenhando um papel importante para o desenvolvimento dessa premissa.

Na obra Uma Teoria da Justiça, John Rawls (2000) evidencia os problemas da estrutura básica da sociedade e dos princípios de justiça, que aparecem como questões importantes para a condição da sociedade, cidadania e virtudes políticas. Rawls apresenta exemplo de sua teoria na situação hipotética da posição original: pessoas com escolhas racionais, possuindo valores morais e políticos caracterizando a objetividade como condição necessária para a justificação, e o véu de ignorância, situação inicial da qual os indivíduos se desconhecendo as consequências dos julgamentos alheios para se chegar a um consenso com equilíbrio reflexivo, se adaptando as questões em jogo, eliminando qualquer possibilidade de intolerância e desajustes.

No entanto, recorda que o equilíbrio não é estável, podendo desatar a situação contratual, contudo, reforça o seu argumento de que ninguém conhece seu lugar na sociedade, caracterizado pela posição original, desse modo, pessoas livres e racionais ajustam seus modos de cooperação. Para isso, Rawls terá como referência o conceito de razão pública de Kant, pressupondo a condição de igualdade e associação de interesses para este fim, estabelecendo assim a raiz de uma democracia constitucional.

Rawls (2000b) considera que os direitos dos indivíduos não devem ser deixados de lado, no entanto, a eles também competem garantir uma situação bem-estar social mais 
abrangente. Dentro do que compreende se tratar de uma sociedade bem ordenada - ou sociedade política, a justiça com equidade só pode ser incorporada com a cooperação de toda a sociedade para o benefício de todos a partir da sua organização em torno da sua estrutura básica.

Essa estrutura é incorporada através das ações e interações sociais com a finalidade de produzir o maior número de bens, atribuindo-lhes uma partilha desses bens reconhecidos, na expressão de direitos a partir do pressuposto de uma ideia intuitiva, como qualificará este resultado hipotético como princípio de justiça procedimental pura, com o dever de aplicar o justo com determinadas restrições sobre qual bem deverá ser divido. O princípio de justiça deve considerar principalmente as diferenças entre as pessoas. Deste modo, refuta a ideia de um indivíduo particularista e uma ideia restritiva de bem-estar ampliando o princípio de equidade.

Partindo deste contexto, iremos analisar o problema da cidadania brasileira nos termos de justiça rawlsianos, envolvendo dois movimentos de atuação política importantes nas decisões políticas do País nos últimos anos: o movimento LGBT e a setorialização das políticas de identidade em torno das políticas públicas, que no início da década de 2000 ganhou abrangência principalmente nas ações das minorias sociais em aproximação com o Estado, e o caso mais recente dos chamados movimentos de renovação política, que tem viabilizado a participação de membros com diversas crenças ideológicos em sua composição, se preocupando com a formação qualificada de pessoas para concorrer a cargos políticos, pautando principalmente por uma renovação parlamentar, incorporando valores éticos e profissionais no exercício da vida pública.

\section{A Difícil Cidadania Substantiva no Brasil}

A universalização dos direitos criou uma constante para o respeito aos valores do todos os cidadãos. Contudo surgem cada vez mais casos de reivindicação de direitos dissociados dos aspectos locais, procurando dar visibilidade a sua identidade cultural, em oposição à uniformidade nacional apoiando-se ao valor das diferenças na articulação das formas específicas de vida, que em geral enfrentam o plano jurídico para o reconhecimento desses valores chamados substantivos.

Entende-se que avanços das instituições democráticas devem ao mesmo passo consolidar os direitos do cidadão, como prescindiam os ideais liberais no século XVIII. Todavia, no Brasil, houve obstáculos para a construção de uma cidadania em conformidade 
com a progressão dos direitos. Entendem-se como dimensões da cidadania: os direitos civis (direito à liberdade, à propriedade e à igualdade perante a lei) direitos políticos (direito à participação, o direito de votar e ser votado), direitos sociais (direito à educação, saúde, e a extensão dos direitos trabalhistas - salário, trabalho justo e aposentadoria). No avançar dos acontecimentos políticos, os direitos humanos (direitos à vida digna, liberdade de expressão, liberdade religiosa), chamados de direitos de quarta geração, passam a ser um componente importante para diminuição da desigualdade dos povos e na promoção da cidadania após anos avassaladores de guerras mundiais.

No Brasil não foi devidamente aplicado, como nos aponta Carvalho (2002b): o direito à liberdade só foi possível após a assinatura da Lei Áurea em 1888, carta que impôs a libertação de negros escravos, que, no entanto, obedece tardiamente uma demanda dos Estados-Nação que já haviam condicionado a liberdade de ex escravos muitos anos antes, o direito ao voto se restringia aos homens de uma determinada classe (fazendeiros e comerciantes), negando o voto aos mais pobres e analfabetos, o direito à saúde, trabalho e educação entrariam vigência a partir da Segunda República em 1930, porém, sua realização teve como consequência a supressão parcial dos direitos civis e políticos, o que de tal maneira centralizou o poder e a possibilidade de ampliar esses direitos na figura do chefe de Estado, e os direitos humanos só aparecem como valor em oposição ao governo militar, contra a intimidação de opositores ao regime e a repressão de classes, que tiveram seus direitos civis e políticos suprimidos.

Para Carvalho (2002b), não se tinha nenhuma relação das massas com as instituições, que estendia as políticas sociais de cima para baixo, possuindo uma forma de governar fazendo a utilização de práticas clientelistas. Houve uma abertura política entre 1945 e 1964, em que os direitos civis e políticos avançaram em descompasso um com o outro, até serem totalmente suprimidos pelo golpe militar de 1964. O Brasil não apresentava organizações da sociedade civil e sindicais fortes o suficiente para fortalecer um regime democrático, tendo um sistema de governo suscetível a um governo autoritário.

A sociedade, como elucidada por Tocqueville (2005), representa a ação que a sociedade ação sobre si mesma, obtendo força suficiente para requerer os processos democráticos, cristalizadas em leis e práticas que tecem a igualdade e a liberdade. Desta forma, estariam os cidadãos condicionados à participação política.

Rawls (2000c) confere ao princípio da participação como organização necessária para evitar uma divisão arbitrária e injusta dos distritos eleitorais, que devem seguir padrões adotados pela constituinte de cada de lugar. 
O princípio da participação também sustenta que todos os cidadãos devem ter um direito igual de acesso, pelo menos num sentido formal, aos cargos públicos. Cada cidadão é apto para participar de partidos políticos, candidatar-se a cargos políticos e ocupar postos de autoridade. Certamente, pode haver qualificações de idade, residência e assim por diante. Mas elas devem razoavelmente estar relacionadas ao cargo; é de se presumir que essas restrições sejam do interesse comum e não discriminem de forma injusta pessoas ou grupos, o que significa que deva afetar a todos igualmente, no curso normal da vida (RAWLS, 2000, p. 224).

Para contornar este problema de raiz histórica no Brasil, organizações e movimentos sociais se unem em torno das políticas públicas fortalecidas enquanto pautas de ação coletiva, que necessitam do reconhecimento do Estado para serem afirmadas, propondo nestes termos a diminuição das desigualdades com ações que busquem sanar as diferenças e opressões contra grupos e organizações menores.

Apesar de ganharem notoriedade em épocas distintas, e possuírem objetivos diferenciados, as novas congregações possuem como local de nascedouro a sociedade civil, que no Brasil se fortaleceu na era da redemocratização em 1985 e como movimentos populares nas décadas entre as décadas de 1980 e 1990. Com isso, desenha-se um cenário para o envolvimento da massa popular e de profissionais que serão representados nos movimentos sociais e nos partidos políticos.

Estes movimentos nascem da evolução da democracia brasileira, que passa a incorporar demandas diversas e a conciliar com os valores e contribuições de diversos atores na política, se ajustando na estrutura que atualmente se apresenta na forma de república federal e constitucional.

\section{O amadurecimento do movimento LGBT no país em torno das políticas de identidade}

As demandas sociais, alvo de contestação pelos movimentos sociais, sociedade civil e representações políticas, têm em sua origem uma concepção de justiça social discutida em territórios que passaram por diversas instabilidades políticas e lidam com as diferenças sociais como um fator de determinante para a realização das políticas de Estado, girando em torno dos princípios econômico, político, social e sustentável, verificadas nos países com democracias estabelecidas, umas das concepções mais presentes giram em torno dos Direitos Humanos de 1948 da $\mathrm{ONU}^{2}$, e institucionalmente como princípio das leis, tem como base a concepção de uma justiça distributiva ${ }^{3}$.

${ }^{2}$ A Organização das Nações Unidas (ONU) é uma organização internacional que nasce da assinatura da Carta das Nações Unidas, instituindo compromissos entre 60 países para resolução dos conflitos e defesa dos direitos 
Em paralelo, a sociedade brasileira, que possui uma democracia restabelecida constitucionalmente, passa por inúmeros problemas de institucionalidade política e um ambivalente juízo ético-moral conservador no tratamento sobre populações vulneráveis, observáveis até os dias de hoje. Uma das mais marcantes foi a ruptura republicana promovida pelas Forças Armadas em 1964 que resultou na Ditadura Militar. Com isso, várias manifestações contrárias ao poder autoritário ganharam as ruas, organizações estudantis, sindicais, artísticas, intelectuais, grupos étnicos e classistas lutaram contra o regime que perduraria por 20 anos.

Ao nos referirmos a esse período, fica marcado a extrema violência física e simbólica praticada pelo regime aos seus contraventores, que provocou o exílio de pessoas fichadas como perigosas ao exército, a tortura contra pessoas consideradas desviantes, como estudantes, artistas, mulheres, e ademais, aos gays, bissexuais, lésbicas e travestis.

Este último público em específico frequentava bares, casas e ruas da cidade durante o período noturno nas grandes metrópoles, o horário favorecia o atendimento aos seus clientes, já que alguns deles e delas trabalhavam com a prostituição ou trabalhavam durante o dia em alguma outra profissão, no entanto, o preconceito social não deixava com que sua sexualidade fosse abertamente assumida.

Durante a ditadura, esses locais sofreram interdição pelo DOI-CODI ${ }^{4}$ e os seus frequentadores passam a ser vítimas dos militares, como há relatos de tortura, abuso sexual e mortes, e mesmo constrangimentos aos funcionários homossexuais que exerciam funções em órgãos públicos. Essas ações faziam parte de uma prática de higienização social, observando atos considerados subversivos e pessoas que classificavam como degeneradas (BARBOSA; ARAÚJO, 2017).

Naquele momento formam-se grupos que procuraram resistir às repressões, atuando em movimentos artísticos e jornais voltados ao público LGBT, com uma forte crítica à ditadura e expectativas na luta por direitos civis. No final da década, os primeiros grupos a

humanos, em decorrência dos desastres da Segunda Guerra Mundial. Sua missão também é solidificar a solidariedade internacional, o respeito aos povos e incentivar a ajuda humanitária às populações em situação de guerra e miséria. O acordo entrou oficialmente em vigência no dia 24 de outubro de 1945.

${ }^{3}$ A discussão está presente na obra "Uma Teoria da Justiça" (1973), que vai justamente recobrir no debate das demandas de populações assistidas pelo Estado. As ações que norteiam os poderes executivo, legislativo e judiciário dos países irão assegurar as reivindicações a partir do entendimento de uma justiça equânime, que prevê a contemplação da pluralidade e de liberdade. Ver em: RAWLS, John. Uma Teoria da Justiça. 1. ed. Martins Fontes, 2000.

${ }^{4}$ O Destacamento de Operações de Informação - Centro de Operações de Defesa Interna (DOI-CODI) foi um órgão comandado pelo exército durante o Regime Militar, que teve como finalidade fichar os principais nomes e organizações que se contrapunham ao poder instaurado pelo golpe orquestrado em 01 de abril de 1964 
promoverem o debate sobre a condição LGBT surgem com características de movimento social, como o Grupo Somos.

A luta LGBT inicia ainda na década de 1960, pertencendo a primeira geração dos movimentos sociais, que buscavam sobretudo as liberdades civis em ditaduras, governos repressivos e apartheid. Neste momento, o homossexual era considerado um problema de saúde, um ser patologizado e subverso ao sistema. A revolta de Stonewall em 1969, que foi resultado da batida policial em um bar frequentado por gays, lésbicas e travestis se tornou símbolo da luta LGBT contra a repressão, o preconceito e as formas de preconizar a resistência contra a opressão.

$\mathrm{Na}$ entrada dos anos 1980, outro fator acaba por influenciar a discriminação em torno dos homossexuais, pela descoberta do vírus da AIDS. A sociedade, influenciada pelas notícias em torno da epidemia, passa ter uma impressão de temor a respeito das pessoas LGBT em geral. Com isso, os grupos representados gays, lésbicas, bissexuais e travestis se organizam em movimentos contra a discriminação, lutando pelos direitos sociais no acesso à saúde e seguridade social.

A intensificação na luta contra a AIDS nos anos 1990 representa uma amplitude da participação de grupos LGBT nas instâncias democráticas, com o surgimento de grupos da sociedade civil e novos movimentos sociais neste período. A sexualidade e o gênero ganham a atenção neste momento como propósitos centrais para estratégias de ativismo político, avançando assim na luta por reconhecimento e em ações revertidas em políticas públicas. Articula-se com os direitos humanos, a sociedade civil e Estada para estabelecer garantias para o exercício da cidadania. O processo de reconhecimento e cidadania se deu em um momento de transição democrática (CARVALHO, 2002c).

Neste período, observa-se a ampliação das discussões sobre políticas de saúde e seguridade. No que diz respeito aos direitos sexuais, a luta pelo atendimento na saúde devido à epidemia de AIDS se torna predominante na reivindicação dos grupos LGBT naquele momento. $\mathrm{O}$ reconhecimento da identidade e do gênero, germinadas ainda na ditadura militar, passam a ter um papel fundamental no interior das ações do movimento LGBT nas suas articulações e reivindicações sociais.

Reconhecidas como valores democráticos, as ações políticas instrumentalizadas na Constituição Federal de 1988 e na luta de movimentos sociais e ONGs para a garantia de políticas públicas, que passam a ser agregados pelos governos na compreensão de sua responsabilidade social. O Plano Nacional de Direitos Humanos (PNDH) foi o primeiro a estender a concepção de direitos sociais à população LGBT. Lançada em 1996 pelo governo 
de Fernando Henrique Cardoso (PSDB), somente na segunda parte do plano em 1998 a seguridade social é associada à inclusão e aos cuidados do Estado.

Por isso, houve a necessidade de ser instaladas áreas técnicas específicas para o cuidado com essas demandas, diretamente subordinado à Presidência da República, como o Ministério dos Direitos Humanos em 1997 pelo governo brasileiro, que atribuiu a diversas pastas ações a serem feitas em áreas de desenvolvimento social para o atendimento desse público.

A discussão de um plano que ofereça a garantia dos direitos sociais para além daqueles já estabelecidos pela carta magna passa a ser incorporado por diversos grupos no âmbito da sociedade civil em encontros, congressos e conferências nos anos 1990. Com o intuito de mobilizar forças para a construção de políticas que garantam a cidadania e o acesso aos serviços públicos, várias entidades encaminharam propostas ao governo brasileiro solicitando atendimento das demandas consideradas primordiais para a população LGBT.

Com status de política pública, os direitos à população LGBT ganha corpo com o programa Brasil Sem Homofobia em 2004, promovido pelo Governo de Luis Inácio Lula da Silva (PT) em seu primeiro ano de mandato. O plano oferece a uma ampla discussão em torno dos direitos sociais no direito à saúde, segurança, educação e reconhecimento social, com isso, as realizações de eventos que aglutinassem as diversas demandas ocorreram nos anos que seguiram como Conferência Nacional de Direitos Humanos LGBT nos anos 2008, 2011 e 2016, o lançamento do I Plano Nacional LGBT em 2009, a organização do Conselho Nacional de Direitos Humanos em 2011 e o programa de Enfrentamento a Violência contra LGBTs em 2013 (IRINEU, 2014).

A partir desta trajetória iniciada nas décadas passadas até o início de década de 2000, exigiu-se uma formação maior dos atores deste campo. Como sujeitos políticos, compreendemos aqui a relação do movimento LGBT numa dinâmica se manifesta entre o público, os espaços de reivindicação e as identidades deste movimento, viabilizando assim a experiências íntimas sejam apreciadas publicamente (IRINEU, 2009).

A diversidade tem sido trabalhada como um conhecimento das formas culturais existentes no mundo, em que suas dinâmicas se ampliam para além do território, promovendo trocas de experiências e uma conscientização acerca das ações que determinam as fixações dos grupos sociais, quando tratamos das relações de poder, hegemonia e regulação da vida. Atualmente, os direitos humanos são representados na forma de direitos fundamentais, na garantia de que leis sejam estabelecidas para o pleno exercício da vida humana em liberdade, igualdade e condições dignas para uma boa relação em sociedade, livre de abusos e violações. 
Isso se deve às mudanças de estrutura do Estado, que passa a identificar pautas de diversos grupos sociais dentro das políticas identitárias. O controle institucional passa a privilegiar o atendimento universal de demandas vindas de organizações, redes e grupos representantes das minorias. Neste contorno, são desenhadas novas políticas de saúde, segurança social e cidadania, que facilitam o acesso dessas pessoas em serviços básicos e qualidade de vida.

Ao longo dos anos, as demandas cresceram e as instituições passam a ter dificuldades em abrigá-las, apesar da amplitude do sistema de proteção social. Os grupos sociais, cada vez mais abrangentes, sentem a necessidade se organizem em torno de suas reivindicações mais específicas, que atendam as diversidades de cada instância. Deste modo, estes grupos se organizam em ações coletivas para pressionar o poder público e obter respostas mais consistentes as suas demandas, como é comum observar questões que demandam reconhecimento do Estado serem debatidas em primeira instância no Supremo Tribunal Federal para depois serem incorporadas nos projetos de lei pela Câmara e o Senado.

\section{Crise na política e o surgimento dos movimentos de renovação política}

A noção de política, condição necessária para o permanente diálogo da sociedade, está sendo depreciada por uma experiência autoritária que anda despejando nesta prática um conluio de interesses de grupos, privilegiando resultados materiais. Ao mesmo passo, o capitalismo financeiro, que passou por uma nova crise recentemente em 2008, acabou com a expectativa de muitos cidadãos e investidores dos mercados financeiros de todo o mundo, gerando desânimo nos governos e a falta de confiança da população nas bases representativas.

A partir de então, os modelos de capital-trabalho se modificam, fazendo com que a aceleração do crescimento industrial acompanhasse a do crescimento econômico, aplicando às forças do mercado novas tecnologias da informação, alterando deste modo as relações entre estado, sociedade e a economia, que passa a flexibilizar ainda mais sua escala de produção e de serviço. Sai de cena a indústria mecanizada e entra em vigor um novo padrão tecnológico de empresas, com reflexos na economia de grande escala, implicando na financeirização e materialização da vida social.

Dentro deste contexto, a experiências pós-republicanas no cenário atual, devido a descrença da população com as instituições, têm sido deturpadas pela ação de autocratas, que aspiram à aversão da política, utilizando de instrumentos antidemocráticos como a reação, a 
desconfiança na verdade, através de articulações incentivadas pelas think tanks ${ }^{5}$, que serviram de porta de entrada para as fake news.

O sistema democrático dos Estados Unidos, sempre muito elogiado por outras nações, viu seus sistemas de direitos e leis que equilibraram por séculos o jogo político tomar rumos indiscriminados em 2016, provocando a desconfiança nas instituições. A República norteamericana operada no sistema de checks and balances (freios e contrapesos) entre os poderes passam a ter suas funções questionadas em operar a favor da cidadania. A eleição do magnata Donald Trump para ocupar o cargo de presidente da República foi o exemplo da radicalização política resultante da descrença com o sistema político estadunidense, reforçando o sentimento de antipolítica.

Num estilo pouco ortodoxo, Trump atacou candidatos democratas e republicanos ao longo da sua Campanha. Na sua longa lista de críticas, Trump salientava o declínio do poder global dos Estados Unidos e a sua exploração por parte de aliados e adversários. Embora de forma errática, Trump articulou um programa de política externa em consonância com a sua narrativa populista e que assentava num discurso antielitista, de desconfiança no conhecimento técnico e cientifico e num forte sentimento de afiliação nacional (PENHA, 2017, p. 11).

Um discurso assentado no nacionalismo, promovendo a entrada de pessoas não especializadas, com aversão ao modelo burocrático das instituições, embalaram a retórica política dos últimos resultados eleitorais na Europa e América do Sul, que decorreu para o lado dos governos de ultradireita, que trazem na bagagem a forte apatia ao conhecimento, ao sistema de justiça social, prejudicando assim a relação geopolítica, ambiental, o diálogo com os países em desenvolvimento e acordos de paz, estabelecidas nas diretrizes das relações diplomáticas.

Nessa lógica, nota-se que configuração política mundial tem passado por muitas transformações significativas. Observou-se um aumento da desconfiança dos cidadãos sobre a democracia representativa, colocando em xeque se esta seria a melhor forma de escolha de governo. A justificativa dessas pessoas está no modo de como a política se apropria da máquina estatal.

Zovatto (2005) aponta que a crise atual dos partidos na América Latina provém, sobretudo, de escândalos provocados por seu financiamento ilegal, atentos aos inúmeros casos

${ }^{5}$ São instituições responsáveis pela produção de ideias sobre políticas públicas, influenciando diretamente na identificação de temas específicos no debate social. Esse serviço tem o objetivo oferecer soluções obtendo aproveitamento nas decisões políticas. Utilizadas em maior proporção nas campanhas políticas, o crescimento dessas empresas nos últimos 10 anos tem sido expressivo, dentre as quais podemos destacar a atuação do Atlas Network, rede que trabalha com uma extensa rede, tendo entorno de 450 fundações parceiras no mundo. 
de corrupção, e que por isso, não seria surpresa para nós que demonização da política por causa do dinheiro estejam tão em alta. Também se faz a crítica de que a participação social estaria cada vez mais imbricada aos interesses políticos. Em consequência disso, o modelo de partido político não estaria cumprido com o seu papel de renovação, tampouco o de cumprir demandas sociais.

Na estrutura política brasileira, a nova tendência percebida nas bases representativas está na atuação de grupos suprapartidários, que compactuam com ideais de superação da velha política, chamados de movimentos independentes de renovação política - organizações de formação política que conjugam como seus lemas a transparência, respeito à democracia, à ética política, com a missão de combater as desigualdades sociais e políticas.

Os primeiros grupos neste formato aparecem no Brasil em 2014, como diagnóstico da inconformidade da juventude que foram às ruas nas Jornadas de Junho de 2013. A imagem da política tradicional brasileira foi comprometida ainda com as investigações de lavagem de dinheiro da Operação Lava Jato em 2014, que até hoje resulta em desdobramentos envolvendo políticos do alto escalão da Câmara, Governo e Senado, além de empresários, o que aprofunda o distanciamento das novas organizações da imagem habitual da política brasileira, geralmente composta por pessoas de meia idade, com alguma atividade profissional notável, ao apostar na escolha de jovens que apresentem características de liderança e habilidade em dialogar com diversos grupos.

Acredita-se que hoje as organizações suprapartidárias no país girem em torno quarenta, dos quais podemos citar: Renova BR, RAPS ${ }^{6}$, Agora!, Acredito, Ocupa Política, Brasil 21, Livres, Frente Favela Brasil, Vote Nelas, Lemann, Nós, Frente Pela Renovação, Bancada Ativista e o mais notável destes o $\mathrm{MBL}^{7}$. Em geral, esses grupos contam com financiamento coletivo feito por pessoas físicas e grupos empresariais ligados à política e a educação. A seleção dos membros para compor as organizações, oferecendo aulas para formação de lideranças políticas e bolsas de estudo para essa finalidade, é feito através de processos seletivos a cada semestre. Não há uma exigência para que logo depois de formados seus membros ingressem na carreira política, porém, muitos acabam fazendo essa escolha.

Os movimentos de renovação política aglutinam em suas fileiras nomes de todos os aspectos ideológicos, inserindo nomes em partidos como o $\mathrm{PDT}^{8}, \mathrm{REDE}^{9}, \mathrm{CIDADANIA}$

${ }^{6}$ Rede de Ação Política Pela Sustentabilidade.

${ }^{7}$ Movimento Brasil Livre.

${ }^{8}$ Partido Democrático Trabalhista.

${ }^{9}$ Rede Sustentabilidade. 
NOVO, PODEMOS, PSDB ${ }^{10}$, PSOL $^{11}$, DEM $^{12}$, SOLIDARIEDADE. Nas eleições de 2018, vários membros desses grupos foram eleitos, destacando as eleições de João Campos (PSBPE), filho do ex governador de Pernambuco e ex candidato à presidência da República já falecido Eduardo Campos, candidato lançado pelo Lemann e Acredito, Tábata Amaral (PDTSP), candidata com formação no Renova BR, RAPS e Acredito, Kim Katagari (DEM-SP), representante do MBL e Sâmia Bonfim (PSOL-SP), do movimento Ocupa Política.

O fator preponderante da alta correspondência dessas organizações está na expectativa proposta de transformar a obsoleta relação entre os representantes políticos e as instituições, e deste modo, tentar a reaproximação da população com a política. Em entrevista concedida ao Estadão, o presidente do Renova BR, Eduardo Mulafej, reforça o objetivo proposto, um pouco antes da disputa eleitoral de 2018 acontecer: "Queremos viabilizar o acesso de pessoas que hoje não estão vinculadas à política ou que não tenham histórico em partidos tradicionais. Ninguém para para (sic) pensar a dificuldade de qualquer pessoa em se candidatar" ${ }^{13}$, desta maneira, garante uma autonomia aos membros em relação a escolha das legendas as quais escolham ingressar, dando ênfase a integração dos seus membros nas atividades partidárias e dos fundamentos práticos na sua educação política.

Boa parte desses grupos buscam fugir da polarização entre esquerda e direita, propondo um plano de renovação diversificado, procurando não se embasar no apoio a características ideológicas dos seus formandos, dando maior destaque ao desempenho e as propostas que contribuam para a revitalização da política, como resultado do conteúdo promovido por essas organizações e da sua fidelidade em contribuir para a formação de líderes ressaltam os valores éticos, políticos e de responsabilidade social. Outra formação suprapartidária que chamou bastante atenção nas últimas eleições foi a chamada candidatura coletiva, originada pelos membros da Bancada Ativista, compostas por membros do PSOL e REDE, que lançou nome de Mônica Sanches (PSOL-SP) nas votações válidas, que levou consigo cinco representantes dos partidos que a ajudarão a compor a cargo parlamentar com ideais em diversos eixos sociais.

Muitas das campanhas dos membros dos movimentos de renovação política não tiveram apoio ou divulgação dos partidos políticos em que foram filiados, mas de pessoas que

\footnotetext{
${ }^{10}$ Partido da Social Democracia Brasileira.

${ }^{11}$ Partido Socialismo e Liberdade.

${ }^{12}$ Democratas.

${ }^{13}$ COTRIM, Jonathas; MAGATTI, Ricardo. Em busca de renovação, grupos buscam partidos para candidaturas cívicas em 2018. ESTADÃO. Disponível em: https://infograficos.estadao.com.br/focas/politico-emconstrucao/materia/em-busca-de-renovacao-grupos-buscam-partidos-para-candidaturas-civicas-em-2018. Acesso em: 04 ago 2019.
} 
fazem parte da organização (dos movimentos sociais e da sociedade civil) e da comunicação dos candidatos nas redes sociais, contando com um forte instrumento de transmissão e mobilização nas novas mídias. Outro fator importante para a estrutura das campanhas dos membros foi recorrer financiamento coletivo através de aplicativos, o que possibilitou a confiança de muitas pessoas nas candidaturas, por se tratar de uma arrecadação pública com transparência, pois a maior fatia do Fundo de Financiamento de Campanha foi repartida para os candidatos que já haviam exercidos mandatos. Segundo dados do jornal O Globo, foram 843 milhões de reais distribuídos aos partidos políticos, e 67\% foram aplicadas nas campanhas de ex senadores e deputados federais ${ }^{14}$.

As legendas partidárias viram com otimismo nas candidaturas de membros oriundos dos grupos de renovação, seguindo a desafio da orientação internacional, foram apontadas como um meio de suprir o esgotamento da imagem dos partidos políticos. Todavia, se aproveitando do desgaste da imagem dos representantes políticos e da queda da confiança na política, as pretensões dessas organizações estariam mais assentadas em reorganizar a estrutura partidária ou a abrir caminhos para uma independência partidária, como já é posto em prática em alguns países, em que se leva em consideração o candidato e não o partido.

\section{Considerações finais}

A concepção de pessoa é um conceito fundamental para entendermos a síntese do tipo de sociedade que Rawls quer representar. O ser moral supõe premissas básicas de convivência, apresentando como fundamentos chave o respeito ao outro, à liberdade, as convicções políticas e deveres morais. Dessa forma, este sujeito estaria carregando consigo uma concepção sobre o que é justo. Contando com a interação social e com a atividade política, funda-se uma sociedade bem ordenada pautada em ideias morais.

Uma sociedade democrática deve pautar-se na razoabilidade, escolhendo os princípios gerais regimentais na relação uns com os outros, que seja garantida como direito fundamental que se aplicaria a todos. Assim, nesse ponto, a cidadania estaria condicionada à justiça como equidade, recaindo aos sujeitos que estipulam este acordo o cumprimento. Os bens primários nada mais são os princípios primeiros que cada pessoa deseja para si, mas que prefira ter em demasiado que em menor proporção, com base nas expectativas sociais, isto é, levará consigo bens como direitos, liberdade, autonomia e igualdade.

${ }^{14}$ PORTINARI, Natália. Políticos Profissionais ficam com $67 \%$ das verbas do fundo eleitoral. O GLOBO, 2018. Disponível: https://oglobo.globo.com/brasil/politicos-profissionais-ficam-com-67-das-verbas-do-fundoeleitoral-23073398. Acesso em: 04 ago 2019. 
Observa-se que nos dois casos apresentados uma questão importante no papel da sociedade política e na formação cidadã: a expressão dos direitos fundamentais e do exercício da ação política. Experimentam-se novas formas de atuação, com foco no desenvolvimento de ideias políticas, na formação de indivíduos representativos, no aumento do conteúdo das intervenções, dando importância em vislumbrar o bom desempenho do exercício dos deveres cívicos e políticos.

Isto se deve ao enraizamento dos valores democráticos, que passaram a contabilizar uma importante marca na cidadania brasileira após a Constituição de 1988, que atribuirá a universalização dos direitos. No entanto, não deverá recair-se ao problema da individualidade, que numa democracia pode ser prejudicial, considerando que nela estão definidos seus termos liberdade e igualdade, que necessita da cooperação social para se manifeste como valor consensual.

Rawls considera a natureza social do cidadão ter grande importância, assim também o poder de exercer sua própria autonomia. Para isso, os indivíduos devem compartilhar de liberdades exercidas em sua plenitude, o que exige um equilíbrio reflexivo sobre os termos de justiça na estrutura básica da sociedade. Não obstante, a liberdade política estaria entre uma das características priorizadas na sua teoria, no entanto, ela deve ter o desfecho na concepção de política de pessoa bem definidas, e ter princípios objetivos que orientem a composição do justo nas instituições políticas, mesmo se tratando de uma sociedade plural.

\section{REFERÊNCIAS}

BARBOSA, Luana Darby Nayrra da Silva; ARAUJO, Valdinei Castro. O papel do Estado e sociedade civil na construção de políticas públicas: uma análise sobre a III Conferência de Direitos Humanos LGBT no Amapá. In: SEMANA DE PÓS-GRADUAÇÃO EM CIÊNCIAS SOCIAIS, 16., 2017. Araraquara. Anais [...]. Araraquara, SP: UNESP, v. 16, 2017. p. 14781495.

CARVALHO, José Murilo de. Cidadania no Brasil. O longo caminho. 3. ed. Rio de Janeiro: Civilização Brasileira, 2002.

IRINEU, Bruna Andrade. A política de previdência social e os direitos LGBT no Brasil. 2009. 111 f. Dissertação (Mestrado em Sociologia) - Universidade Federal de Goiás, Faculdade de Ciências Sociais, 2009. Disponível em: https://files.cercomp.ufg.br/weby/up/109/o/Disserta\%C3\%A7\%C3\%A3o_-_Sociologia__Bruna_Irineu_-_Final.pdf. Acesso em: 04 ago 2019.

VINHA, Luís da. Previsivelmente incoerente: Uma análise preliminar da política externa de Donald Trump. Relações Internacionais (R: I), Lisboa, n. 55, p. 9-33, set. 2017. Disponível em: http://www.scielo.mec.pt/pdf/ri/n55/n55a02.pdf. Acesso em: 04 ago 2019. 
RAWLS, John. Uma teoria da justiça. 1. ed. São Paulo: Martins Fontes, 2000. 709p.

TOCQUEVILLE, Alexis. Democracia na América: livro 1 - leis e costumes. São Paulo: Martins Fontes, 2005. 566p.

ZOVATTO, Daniel. Financiamento dos partidos e campanhas eleitorais na América Latina: uma análise comparada. Opinião Pública, v. 11, n. 2, p. 287-336, 2005.

\section{Como referenciar este artigo}

BARBOSA, Luana Darby Nayrra da. Cidadania, Políticas de Identidade e Renovação Política: Um debate à luz da Teoria da Justiça de John Rawls. Rev. Sem Aspas, Araraquara, v. $\quad 8, \quad$ n. 2 , p. 152-166, jul./dez., 2019. e-ISSN: 2358-4238. DOI: https://doi.org/10.29373/sas.v8i2.13106

Submetido em: 11/11/2019

Revisões requeridas: 20/11/2019

Aprovado em: 10/12/2019

Publicado em: 30/12/2019 